J. Amer. Soc. Hort. Sci. 115(2):312-319. 1990.

\title{
Inheritance of Isocitrate Dehydrogenase, Malate Dehydrogenase, and Shikimate Dehydrogenase in Peach and Peach $\times$ Almond Hybrids
}

\author{
Bruce D. Mowrey and Dennis J. Werner \\ Department of Horticultural Science, North Carolina State University, Box 7609, Raleigh, \\ NC 27695-7609 \\ David H. Byrne \\ Department of Horticultural Science, Texas A\&M University, College Station, TX 77843-2133 \\ Additional index words Prunus, allozyme, isozyme, electrophoresis, fruit breeding
}

\begin{abstract}
Eighteen isozyme systems were surveyed in the peach [Prunus persica (L.) Batsch.] plant introduction collection. Seven systems were polymorphic. Three previously unreported isocitrate dehydrogenase (IDH; EC 1.1.1.41), three malate dehydrogenase (MDH; EC 1.1.1.37) and two shikimate dehydrogenase (SDH; EC 1.1.1.25) banding patterns were detected in the clones. Isocitrate dehydrogenase was dimeric in structure, with two alleles present at a single locus. Malate dehydrogenase was dimeric in structure, with three alleles present at the fast locus, while a second locus was monomorphic. Shikimate dehydrogenase was monomeric, with one allele present in most clones, while PI 113452, PI 113650, and PI 117679 were heterozygous for a slow SDH allele. Electrophoretic evidence suggests PI 113452, PI 113650, and PI 117679 are peach $\times$ almond $(P$. dulcis Webb) hybrids, since they were heterozygous for alleles previously reported only in almond.
\end{abstract}

One of the main uses of isozyme analysis is to facilitate development of genetic maps through linkage studies. Isozymes have been used extensively to study gene linkage in Zea mays L. (Goodman et al., 1980b; Stuber et al., 1988) and Lycopersicon esculentum (Tanksley and Rick, 1980), and to a lesser extent in other plant species. Polymorphism is a prerequisite for use of isozymes in linkage studies. Little isozyme polymorphism has been found in peach, despite variability for numerous morphological traits. Peach is perhaps the best genetically characterized fruit tree species, with 27 simply inherited morphological traits (Hesse, 1975; Monet et al., 1985). Since peach is diploid $(2 \mathrm{n}=2 \mathrm{x}=16)$, it is unusual that only two linkage groups have been reported (Hesse, 1975; Monet et al., 1985). Isozyme loci provide an opportunity to identify additional linkage groups. Previous research has identified polymorphism in

Received for publication 14 Nov. 1988. Paper no. 11908 of the Journal Series of the North Carolina Agricultural Research Service, Raleigh, NC 27695-7601. We gratefully acknowledge the assistance of Jose X. Chaparro in production of the seedling populations used in this study. We thank Brenda Bateman, Dianne Beattie, Sylvia Boles, and Elizabeth Terrel for advice on electrophoretic techniques. The cost of publishing this paper was defrayed in part by the payment of page charges. Under postal regulations, this paper therefore must be hereby marked advertisement solely to indicate this fact. six enzyme systems (Arulsekar et al., 1986b; Durham et al., 1987; Messeguer et al., 1987).

To date, most peach isozyme studies have been performed using commercial cultivars (Arulsekar et al., 1986b; Messeguer et al., 1987) or selections and seedling populations from breeding programs (Durham et al., 1987). North American peach cultivars have a narrow genetic base (Scorza et al., 1985), and it is possible that isozyme variants not present in North American cultivars exist within the species. Additional variation should be found in the USDA peach plant introduction collection because it is composed of clones from various geographical locations, including China, the center of diversity for peach (Zeven and Zhukovs\&, 1975). These clones are highly variable for bloom date, fruit size and quality, and other traits (Ackerman, 1957; Ackerman et al., 1955).

The objectives of this study were to examine 56 clones representing the USDA peach plant introduction collection to 1) determine the inheritance of any previously unreported isozyme markers found in the clones, and 2) compare polymorphism in the collection with previously documented populations.

\section{Materials and Methods}

Fifty-six peach plant introductions (Table 1) were examined. Partially to fully expanded leaves were collected from actively 
Table 1. Peach plant introduction (PI) clones examined, their place of origin and respective malate dehydrogenase (MDH) phenotypes and isocitrate dehydrogenase (IDH) genotypes

\begin{tabular}{|c|c|c|c|c|}
\hline \multirow{2}{*}{$\frac{\text { PI\# }}{34685}$} & \multirow[t]{2}{*}{ Clone } & \multirow{2}{*}{$\frac{\text { Origin }}{\text { Pakistan }}$} & \multicolumn{2}{|c|}{ 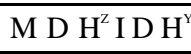 } \\
\hline & & & $B$ & $A$ \\
\hline 36126 & Bolivian Cling & Bolivia & $B$ & $C$ \\
\hline 43289 & Ying Tsui Tao & China & $A$ & $C$ \\
\hline 55776 & Seed importation & China & $B$ & $C$ \\
\hline 62602 & Pi Tao & China & $B$ & $A$ \\
\hline 63850 & Shalil seedling & India & $A$ & $A$ \\
\hline 65821 & Shari Thai Tao seedling & China & $E$ & $C$ \\
\hline 65974 & $\operatorname{De} C \cos a(n)$ & Italy & $A$ & $C$ \\
\hline 65977 & Gialla di Padova(n) & Italy & $B$ & $A$ \\
\hline 77876 & Tos China \#1 & China & $D$ & $B$ \\
\hline 78544 & Terzarola Col Pizzo & Italy & $B$ & $C$ \\
\hline 82413 & Baladi No. 1 & Israel & $B$ & $A$ \\
\hline 93826 & Inkoos & South Africa & $B$ & $A$ \\
\hline 95501 & Seed importation & China & $D$ & $A$ \\
\hline 101663 & Ta Tao No. 1 (= Feicheng Tao No. 1$)$ & China & $D$ & $A$ \\
\hline 101667 & Ta Tao No. 5 (= Feicheng Tao No. 5) & China & $A$ & $A$ \\
\hline 101668 & Ta Tao No. 6 (= Feicheng Tao No. 6) & China & $A$ & $A$ \\
\hline 101686 & Ta Tao No. 24 (= Feicheng Tao No. 24) & China & $A$ & $A$ \\
\hline 101823 & Bienvenida No. 65 & Morocco & $A$ & $C$ \\
\hline 101835 & Precoce d'Ampuis No. 56 & Morocco & $B$ & $A$ \\
\hline 102705 & No. 501 & USSR & $A$ & $A$ \\
\hline 104287 & Soleil d'Octobre & Morocco & $B$ & $A$ \\
\hline 104488 & Gaschina Novembre & Italy & $D$ & $B$ \\
\hline 105362 & Genovese & Italy & $B$ & $C$ \\
\hline 106062 & Killiekrankie & South Africa & $F$ & $C$ \\
\hline 112032 & Saharanpur No. 1 & India & $E$ & $C$ \\
\hline 112033 & Saharanpur No. 2 & India & $B$ & $B$ \\
\hline 113452 & Rogani-Gow & USSR & $D$ & $C$ \\
\hline 113455 & P. persica spp. ferganensis No. 0244 & USSR & $B$ & $C$ \\
\hline 113650 & Pollardi & Italy & $B$ & $C$ \\
\hline 117679 & No. 01370 & USSR & $D$ & $C$ \\
\hline 119840 & No. 0195 & Turkey & $E$ & $C$ \\
\hline 119844 & No. 0932 & Turkey & $B$ & $C$ \\
\hline 119846 & No. $1383-\mathrm{T}$ & Turkey & $C$ & $C$ \\
\hline 125017 & Sary Oiler(n) & USSR & $A$ & $B$ \\
\hline 125025 & China Flat & India & $E$ & $A$ \\
\hline 129674 & Angel & South Africa & $E$ & $C$ \\
\hline 129678 & Stanwick(n) & South Africa & $B$ & $C$ \\
\hline 130980 & Proskauer & Germany & $B$ & $C$ \\
\hline 131034 & Spathe de Hallen & Poland & $E$ & $C$ \\
\hline 131075 & Violette Hative(n) & England & $B$ & $C$ \\
\hline 131209 & Pineapple(n) & England & $B$ & $C$ \\
\hline 132007 & Rheingold & Germany & $B$ & $C$ \\
\hline 133551 & Peregrine & Australia & $B$ & $C$ \\
\hline 133741 & Lady Palmerston & Australia & $D$ & $C$ \\
\hline 133982 & Herholdt's Late Cling & South Africa & $B$ & $C$ \\
\hline 133984 & Marina & South Africa & $B$ & $C$ \\
\hline 133987 & Nooiens Herholdt's strain & South Africa & $B$ & $C$ \\
\hline 134150 & Bresquillo Duranzos (PI 43569) seedling & Spain & $B$ & $C$ \\
\hline 134151 & Transvaal yellow cling (PI 87637) seedling & South Africa & $B$ & $A$ \\
\hline 134401 & PI 80089 seedling & China & $A$ & $A$ \\
\hline 146137 & No. 142058 (PI 105057) seedling & USSR & $B$ & $B$ \\
\hline 151158 & Jorge (Royal George) & Argentina & $B$ & $C$ \\
\hline 240928 & Mao Tao (PI 107838) seedling & China & $D$ & $A$ \\
\hline 442378 & Select seedling & Mexico & $B$ & $C$ \\
\hline 442380 & Select seedling & Mexico & $B$ & $C$ \\
\hline
\end{tabular}

${ }^{2} A=M d h 1-31 M d h 1-3 ; B=M d h 1-2 / M d h 1-2 ; C=M d h 1-1 / M d h 1-1 ; D=M d h l-2 /$

Mdh1-3; $E=M d h 1-2 / M d h 1-1 ; F=M d h 1-1 / M d h l-3$.

${ }^{y} A=I d h 1-3 / I d h 1-3 ; B=I d h 1-3 / I d h 1-2 ; C=I d h 1-2 / I d h 1-2$.

${ }^{\mathrm{x}} \mathrm{n}=$ nectarine.

growing shoots of field-grown trees. Immature leaves had the highest levels of enzyme activity, except for peroxidase and esterase enzymes, which showed greater activity in mature leaves. Mature leaves were collected $=0.3 \mathrm{~m}$ from the shoot terminal when sampling for peroxidase and esterase staining. Samples were collected within $24 \mathrm{hr}$ of electrophoresis and stored at $\approx 4 \mathrm{C}$. 
Electrophoretic procedures used were similar to those of Stuber et al. (1988). Samples were prepared by grinding $400 \mathrm{mg}$ of leaf tissue, $5 \mathrm{ml}$ of extraction buffer (Arulsekar and Parfitt, 1986 ), and $\approx 400 \mathrm{mg}$ of insoluble polyvinylpyrrolidone with a polytron (Model \# PT 1020 350D, Brinkmann Instruments, Westbury, N.Y.). Sample tubes were kept in crushed ice, except for 5 to $10 \mathrm{sec}$ during grinding. The extract was absorbed onto filter paper wicks that were blotted on a paper towel, then loaded into starch gels prepared with $29.8 \mathrm{~g}$ Connaught starch, $15 \mathrm{~g}$ Electrostarch, $15 \mathrm{~g}$ sucrose. and $340 \mathrm{ml}$ of gel buffer (Stuber et al., 1988):

Histidine-citrate $\mathrm{pH} 5.0$ (HIS), histidine-citrate $\mathrm{pH} 6.5$ (HIS6.5), lithium-borate/Tris. citrate pH 8.3 (LBTC) (Stuber et al., 1988), and morpholine-citrate pH 6.1 (MC) (Conkle et al., 1982) gel buffers were used. The MC buffer system was modified slightly by using one-half-strength buffer in the gel and buffer tanks. Gels were run at $13.5 \mathrm{~W}$ constant power in a refrigerator maintained at $4 \pm 1 \mathrm{C}$. Ice packs were placed on the gels for additional cooling. Wicks were removed from the gels after 10 to $15 \mathrm{~min}$ to improve staining resolution. HIS, HIS6.5, and LBTC gels were run for $6 \mathrm{hr}$, except when staining for peroxidase and esterase, in which case LBTC gels were run for $4 \mathrm{hr}$. MC gels were run for $7.5 \mathrm{hr}$. Following electrophoresis, gels were sliced horizontally, yielding six 2-mm-thick slices. The top slice was discarded, except when staining for leucine aminopeptidase and menadione reductase, which required 4-mm-thick slices.

Isozyme systems surveyed included acid phosphatase (ACP; EC 3.1.3.2), alcohol dehydrogenase (ADH; EC 1.1.1.1), aspartate aminotransferase (AAT; EC 2.6.1.1), catalase (CAT EC 1.11.1.6), esterase (EST; EC 3.1.1.1), glutamate dehydrogenase (GDH; EC 1.4.1.2), glucosephosphate isomerase (GPI; EC 5.3.1.9), IDH, 'malic' enzyme (ME; EC 1.1.1.40), MDH, phosphoglucomutase (PGM; EC 2.7.5.1), 6-phosphogluconic dehydrogenase (PGD; EC 1.1.1.44), SDH (Stuber et al., 1988), peroxidase (PER; EC 1.11.1.7), leucine amino-peptidase (LAP; EC 3.4.11.1) (Andsekar and Parfitt, 1986), aldolase (ALD; EC 4.1.2..13), glucose-6-phosphate dehydrogenase (G6PD; EC 1.1.1.49), and menadione reductase (MNR; EC 1.6.99.2) (Conkle et al., 1982). ACP, ADH, IDH, G6PD, PGD, SDH, ME, and MNR were stained on MC gels; CAT, EST, AAT, GPI, LAP, and PER staining was performed on LBTC gels; and GDH, PGM, ALD, and MNR were stained on HIS6.5 gels. MDH staining was performed on both MC and HIS.

Migration distances were recorded to the nearest $0.5 \mathrm{~mm}$. A relative migration $\left(R_{m}\right)$ was computed from the ratio of each isozyme band to the fastest-migrating band of 'Redhaven' peach within an enzyme system. In systems with multiple loci, the locus with greatest anodal migration was designated as 1 , slowermigrating loci were assigned progressively higher numbers. Putative alleles at each polymorphic locus were named similarly, with the fastest-migrating allele being designated 1 allele and slower migrating alleles assigned progressively higher numbers.

\section{Results and Discussion}

MDH, IDH, SDH, PGD, LAP, \&4T, and PGM were polymorphic within the plant introductions, while ADH, ALD, GDH, GPI, ME, PER, and G6PD were monomorphic. ACP, CAT, EST, and MNR could not be characterized due to inconsistent staining, but also appeared polymorphic.

Isocitrate dehydrogenase. Three banding patterns, designated $I d h A, I d h B$, and $I d h C$, were observed at the main staining region for IDH (Fig. 1). Fainter-staining bands migrating both ahead and behind the main staining region were sometimes detected, but they were not characterized due to staining inconsistency. All three banding patterns were characterized by the presence of a darkly staining region and a faster-migrating, lighter-staining "shadow" region. Shadow bands were not detected on some occasions; therefore, $R_{m}$ calculations were based on migration of the main band. IdhC was the most common banding pattern and had a $R_{m}$ of 1.00 . The $\operatorname{IdhB}$ banding pattern was present in only five of the clones examined. This banding pattern usually appeared as a single diffuse main band with a $R_{m}$ of 0.98 and a lightly staining diffuse shadow band; however, when resolution was good, three separate bands, with $R_{m} s$ of $1.00,0.98$, and 0.95 could be distinguished in the main banding region. The $l d h A$ phenotype was present in 17 of the clones and had a $R_{m}$ of 0.95 .

Segregation data from three crosses and two self-pollinations

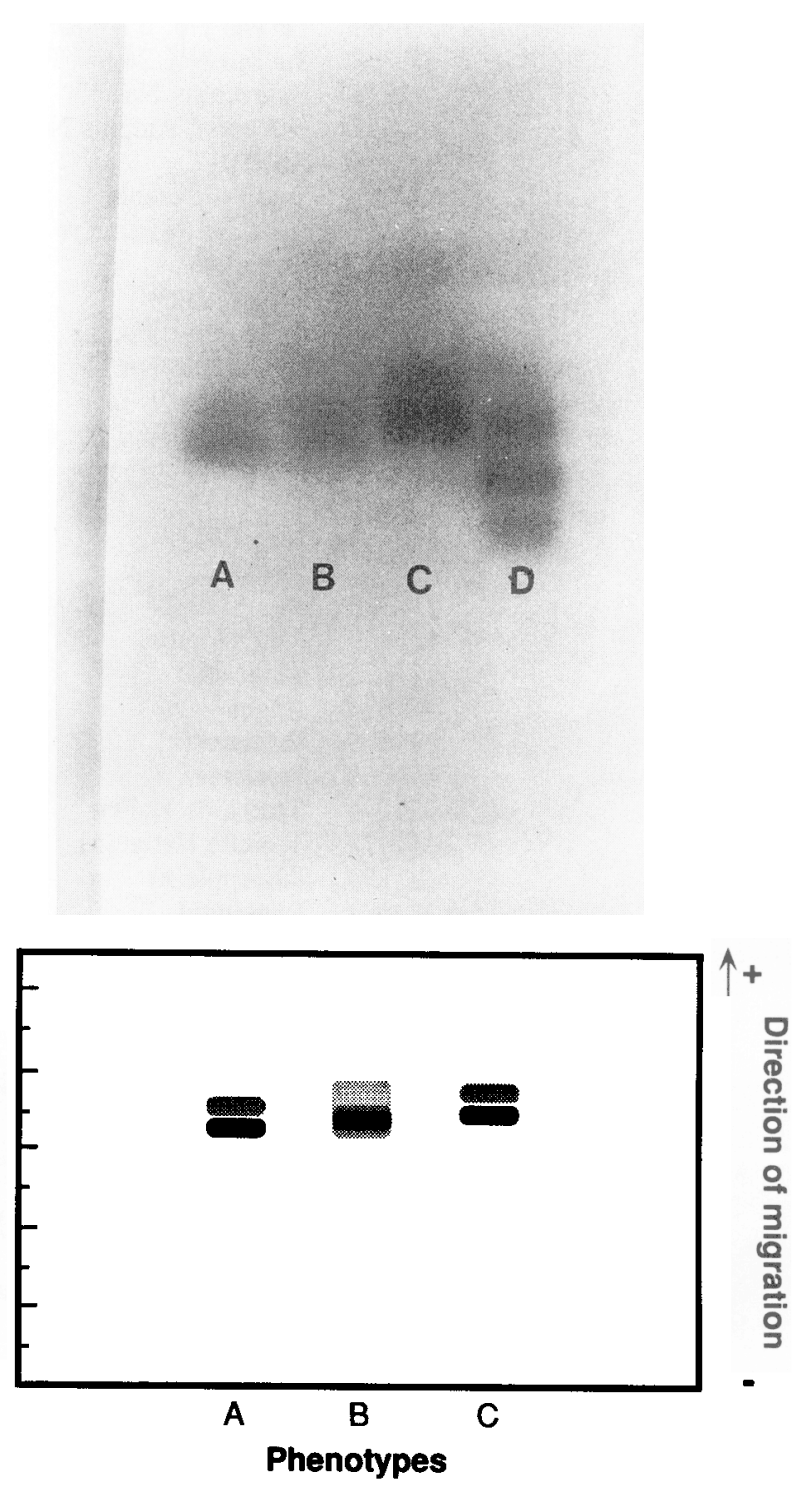

Fig. 1. Photograph and diagram of $I d h A$ (A) $I d h B$ (B), and $I d h C$ (C) isocitrate dehydrogenase phenotypes observed in peach plant introductions. NC 10254 (D in photograph) is heterozygous for an Idh1 allele not detected in peach plant introductions and displays a heterodimeric band. 
suggest that staining in the main IDH region was due to activity of a single locus possessing 2 alleles, Idh1-2 and Idh1-3 (Table 2). Allelic designations of $l d h 1-2$ and Idh1-3 were used, since a faster-migrating IdhI allele is present in close relatives of peach (Mowrey, unpublished data). The Idhl-2 and Idhl-3 alleles had $R_{m}$ values of 1.00 and 0.95 , respectively. "Dimeric structure of the enzyme was indicated by the presence, of a heterodimeric band with a $R_{m}$ of 0.98 in heterozygous individuals. Heterozygous clones usually displayed a banding pattern that appeared to be a single, diffuse band, since average migration of the two alleles differed by only $2 \mathrm{~mm}$. This diffuse band was actually three overlapping bands. Dimeric structure of the enzyme was further indicated in NC 10254, a peach $\times$ almond hybrid heterozygous for an allele with $R_{m}$ of 0.78 . A heterodimeric band was clearly present in this clone (Fig. 1). The Idh1-2 allele was most common in the plant introductions with a frequency of $65 \%$. Low frequency of heterozygous individuals in the plant introductions was probably due to the high rates of self-pollination that occur in peach. Variants in IDH have been reported in peach pollen (Messeguer et al., 1987), but the same alleles may not be responsible, since different loci maybe active in pollen (Tanksley et al., 1981). The unexpected seedlings in the Idh1-2/Idh1-2 class in the cross PI 104488 (Idh1-2/Idhl-3) $\times$ PI 101668 (IdhI-3/Idh1-3) are probably due to accidental selfpollination or outcrossing.

Malate dehydrogenase. Six MDH banding patterns (Figs. 2 and 3) were detected in this study and identified as phenotypes A-F (Table 1). Staining of MDH was performed on both HIS and $\mathrm{MC}$ to distinguish bands with similar migrations on a given gel system. A total of 14 bands was detected on HIS gels (Fig. 2), while 13 bands were detected on MC (Fig. 3). Bands could be detected on each system that were not detectable on the other system. Individual bands were numbered from fastest to slowest on HIS. The same numbers were used to identify bands observed on MC. The band present on MC, but not on HIS, was identified as band 10.5, because it migrated near HIS band 10 . The $\mathrm{R}_{\mathrm{m}}$ values of bands on HIS were $1.75,1.57,1.21,1.19$, $1.02,1.00,0.98,0.81,0.80,0.63,0.55,0.40,0.34$, and 0.19 for bands 1 through 14, respectively. On MC the band $R_{m} s$ were $1.40,1.22,1.12,1.10,1.00,0.94,0.91,0.80,0.79,0.78$, $0.71,0.65$, and 0.58 for bands $1,2,3,4,5,6,9,7,10,10.5$, 11,13 , and 14 , respectively.

The $M d h A$ phenotype consisted of four bands when observed on MC (Fig. 3), and five bands on HIS (Fig. 2). This phenotype was observed in 10 clones and has not been previously reported. to the best of our knowledge. The difference in band numbers between the two systems is presumed to be due to comigration of HIS bands 13 and 12 on MC.

Table 2. Genotypic ratios of goodness-of-fit for isocitrate dehydrogenase in peach crosses.

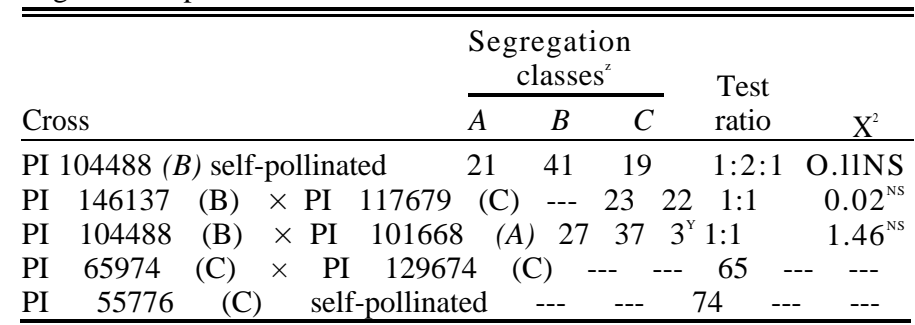

${ }^{2} A=\operatorname{Idh} A, B=\operatorname{IdhB}, C=\operatorname{IdhC}$.

${ }^{y}$ Genotypes arising from accidental self-pollination not included in $\mathrm{x}^{2}$ calculations.

${ }^{\mathrm{NS}}$ Nonsignificant.
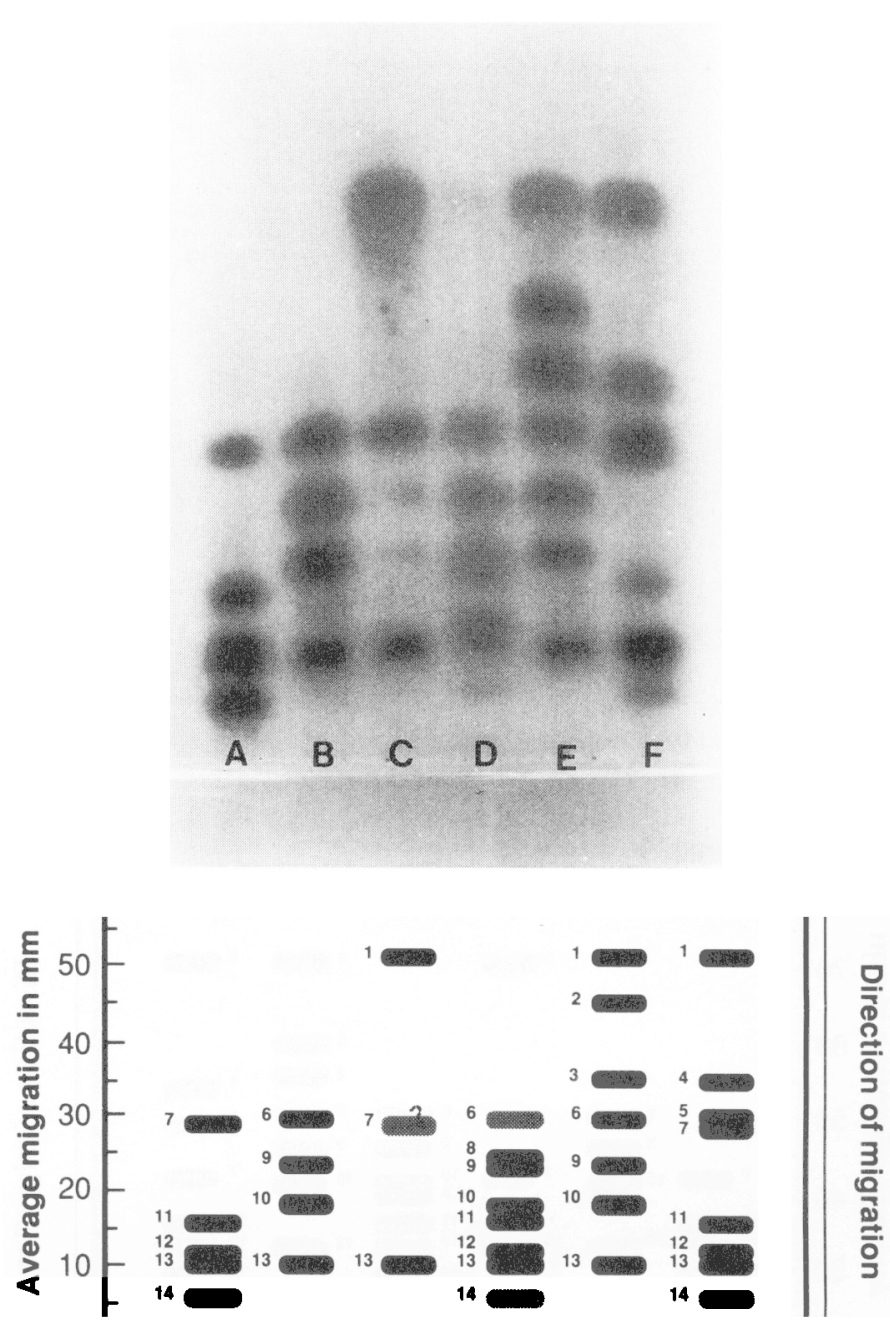

\section{Phenotypes}

Fig. 2. Photograph and diagram of $\operatorname{MdhA}(\mathrm{A}), \operatorname{MdhB}(\mathrm{B}), \operatorname{MdhC}(\mathrm{C})$, $M d h D(\mathrm{D}), M d h E(\mathrm{E})$, and $M d h F(\mathrm{~F})$ malate dehydrogenase phenotypes observed in peach plant introductions when stained on histidine-citrate ( $\mathrm{pH}$ 5.0) buffer system.

The $M d h B$ phenotyue was the most common within the plant introductions, occuring in 30 clones. This has also been reported to be the most common phenotype in commercial cultivars (Arulsekar et al., 1986b) and the Univ. of Florida peach breeding program (Durham et al., 1987).

The $M d h C$ phenotype occurred only in PI 119846. This phenotype consisted of three bands (Figs. 2 and 3), with the middle band staining somewhat lighter than the other two. The fast band consistently stained darker than all other bands. This phenotype resembles the F/F phenotype described by Durham et al. (1987); however, there are some discrepancies. Durham et al. (1987) reported that the intermediate band in their F/F phenotype had a $R_{m}$ equal to the fastest-migrating band in the most common banding pattern. In this study, the $R_{m}$ of the intermediate band differed slightly from the $R_{m}$ of the fastest-migrating band of the $M d h C$ phenotype when observed on HIS, and the two bands differed considerably when stained on MC. The MdhC phenotype observed in the plant introductions also differs from the homozygous fast phenotype described by Arulsekar et al. 


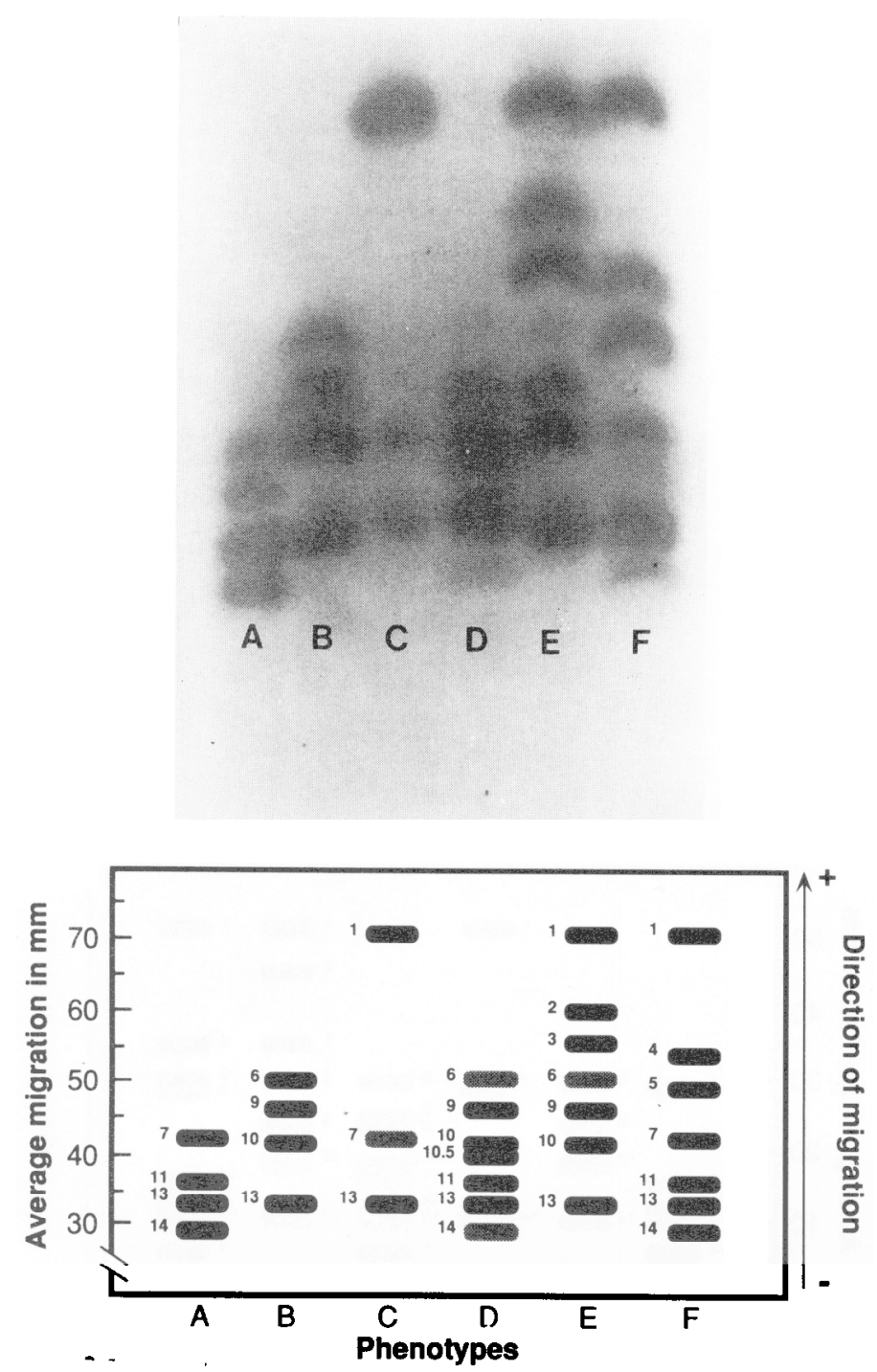

Fig. 3. Photograph and diagram of $M d h A$ (A), $M d h B$ (B), $M d h C$ (C), $M d h D(\mathrm{D}), M d h E(\mathrm{E})$, and $M d h F(\mathrm{~F})$ malate dehydrogenase phenotypes observed in peach plant introductions when stained on morpholine.citrate ( $\mathrm{pH}$ 6.1) buffer system.

(1986b). The homozygous fast phenotype described by Amlsekar et al. (1986b) was similar to the MdhC phenotype observed in the plant introductions, except for the presence of two additional bands between the slowest- and intermediate-migrating bands.

Peach clones Fla. W1-1 [F/F, Durham et al., 1987] and 'Chinese Cling' [F/F, Arulsekar et al., 1986b] were examined in this study and found to be identical to the $M d h C$ phenotype. Differences may be due to differences in buffer systems used. Arulsekar et al. (1986b) used histidine. $\mathrm{HCl}$ pH 7.0, while Durham et al.(1987) used histidine-citrate $\mathrm{pH}$ 5.7.

The $M d h D$ phenotype was observed in eight plant introductions. This phenotype consisted of eight bands when observed on HIS; however, only seven bands were observed on MC gels. The difference in band numbers between the buffer systems is presumed to be due to the same phenomenon observed in the $M d h C$ phenotype. This phenotype was difficult to characterize due to overlapping of bands.

The MdhE banding pattern was present in six clones and consisted of seven bands. The $M d h F$ possessed seven bands when observed on MC (Fig. 3), and eight bands when stained on HIS (Fig. 2). Differences in band number between buffer systems are thought to be due to comigration of bands 13 and 12 on MC. Overlapping of bands 5 and 7 on HIS sometimes produced what appeared to be a seven-banded phenotype. This phenotype was present only in PI 106062.

Previous investigators (Arulsekar et al., 1986b; Durham et al., 1987) have determined that the $M d h B$ and $M d h C$ phenotypes were produced by different alleles in the homozygous state and the MdhE phenotype is produced by these alleles in a heterozygous state. Segregation data from cross PI $146137(M d h B) \times$ PI 129674 (MdhE) and self-pollinations of PI $119840(M d h E)$, PI $129674(M d h E)$, and PI $55776(M d h B)$ (Table 3) further support the hypothesis that the $M d h B$ and $M d h C$ phenotypes are produced in individuals homozygous for the Mdhl-2 and Mdhl1 alleles, respectively. The MdhE phenotype is produced in individuals heterozygous for these alleles. Although PI 119846 was not used in crossing, segregation ratios observed from selfpollinations of PI 129674 and PI 119840 (both $M d h E$ ) indicate the $M d h C$ phenotype is produced by an allele in the homozygous condition.

Self-pollination of PI 65974 (MdhA) indicates this phenotype is due to homozygosity for a previously unreported slow (Mdhl3) allele, since only $M d h A$ seedlings were produced. Likewise, the $M d h D$ phenotype is produced when individuals are heterozygous for the Mdhl-2 and Mdhl-3 alleles. The cross of PI $146137(M d h B) \times$ PI $101668(M d h A)$ produced only $M d h D$ seedlings, as expected when crossing two homozygous genotypes. The cross of PI $104488(M d h D) \times$ PI $101668(M d h A)$ produced an expected segregation of $1 M d h A: 1 M d h D$ (Table 3). The seven $M d h B$ seedlings are probably due to accidental self-pollinations or outcrossing.

Skewed segregation ratios were obtained in one cross and one self-pollination involving the $M d h D$ phenotype. Self-pollination of PI $104488(M d h D)$ showed a marked skewing toward the $M d h B$ and $M d h D$ phenotypes, while the cross of PI 146137 $(M d h B) \times$ PI $117679(M d h D)$ was skewed toward the $M d h B$ phenotype. Self-pollinations were ruled out as the cause of the skewing in PI $146137 \times$ PI 117679 , because the seed parent is male-sterile. Also, outcrossing was not a likely cause of skewing in the PI 104488 self-pollination, since flowering branches were enclosed in a fine-meshed nylon cloth during bloom to exclude bees.

The $M d h l-1$ allele is fond in commercial germplasm at low frequencies, possibly due to some type of selection pressure against the allele (Arulsekar et al., 1986b). Although no significant skewing of segregation ratios was noted in crosses and self-pollinations involving the $M d h l-l$ allele, it is possible the Mdhl-3 and Mdhl-1 alleles have reduced viability in certain genetic backgrounds. This would explain the high frequency of the $M d h l-2$ allele in all populations examined so far and the skewed segregation ratios obtained in the aforementioned cross and self-pollination.

The cross PI $104488(M d h D) \times$ PI $129674(M d h E)$ gave a segregation ratio that was not significantly different from the expected ratio of $1 M d h B: 1 M d h D: 1 M d h E: 1 M d h F$, indicating the observed variation in the population was due to polymorphism at one locus. An open-pollinated seedling population from PI $106062(M d h F)$ also was examined in this study. PI 106062 is male-sterile and blooms too early for dependable seed production under the usual climatic conditions of Raleigh, N. C.; consequently, it was not used in controlled crosses. How- 
Table 3. Phenotypic ratios and goodness-of-fit for malate dehydrogenase in peach crosses.

\begin{tabular}{|c|c|c|c|c|c|c|c|c|}
\hline \multirow[b]{2}{*}{ Cross } & \multicolumn{6}{|c|}{ Segregation classes $^{z}$} & \multirow{2}{*}{$\begin{array}{l}\text { Test } \\
\text { ratio }\end{array}$} & \multirow[b]{2}{*}{$\chi^{2}$} \\
\hline & $A$ & $B$ & $C$ & $D$ & $E$ & $F$ & & \\
\hline PI $104488(D) \times$ PI $129674(E)$ & $\cdots$ & 13 & --- & 10 & 24 & 13 & $1: 1: 1: 1$ & $5.58^{\mathrm{NS}}$ \\
\hline PI $104488(D)$ self-pollinated & 11 & 23 & --- & 56 & --- & --- & $1: 1: 2$ & $8.05^{* *}$ \\
\hline PI $129674(E)$ self-pollinated & $\because$ & 21 & 24 & $\cdots$ & 42 & -- & $1: 1: 2$ & $0.29^{\mathrm{NS}}$ \\
\hline PI $119840(E)$ self-pollinated & $\therefore$ & 8 & 12 & $\cdots$ & 24 & -- & $1: 1: 2$ & $1.08^{\mathrm{NS}}$ \\
\hline PI $104488(D) \times$ PI $101668(A)$ & 31 & $7^{y}$ & $\cdots$ & 30 & --- & -- & $1: 1$ & $0.02^{\mathrm{NS}}$ \\
\hline PI $146137(B) \times$ PI $129674(E)$ & $\cdots$ & 70 & --- & 57 & $\cdots$ & -- & $1: 1$ & $1.41^{\mathrm{NS}}$ \\
\hline PI $146137(B) \times$ PI $117679(D)$ & --- & 32 & --- & 15 & $-\cdots$ & --- & $1: 1$ & $5.33^{*}$ \\
\hline PI $65974(A) \times$ PI $117679(D)$ & 16 & -.- & --- & 21 & -- & -- & $1: 1$ & $0.64^{\mathrm{NS}}$ \\
\hline PI $65974(A) \times$ PI $129674(E)$ & $1^{y}$ & $\cdots$ & --- & 32 & $\cdots$ & 32 & $1: 1$ & $0.00^{\mathrm{NS}}$ \\
\hline PI $65974(A)$ self-pollinated & 48 & $\cdots$ & --- & --- & $\cdots$ & -- & --- & $\cdots$ \\
\hline PI $55776(B)$ self-pollinated & --- & 74 & -- & --- & --- & --- & $-\cdots$ & $\cdots$ \\
\hline PI $146137(B) \times$ PI $101668(A)$ & --- & $\ldots$ & -- & 88 & -- & --- & $\cdots$ & $\cdots$ \\
\hline
\end{tabular}

${ }^{2} A=M d h A, B=M d h B, C=M d h C, D=M d h D, E=M d h E, F=M d h F$.

${ }^{y_{G}}$ enotypes arising from accidental self-pollination not included in $\chi^{2}$ calculations.

NS,*,**Nonsignificant or significant at $P=0.05$ or 0.01 , respectively.

ever, 1987 climatic conditions were such that heavy fruit set was obtained on PI 106062. PI 106062 bloomed with PI 129674 $(\mathrm{MdhE})$ and $=3$ weeks before most male-fertile clones in the planting. Therefore, most seed produced on PI 106062 was due to crossing with PI 129674. A segregation of $6 \mathrm{MdhA}: 23 \mathrm{MdhC}$ : $16 \mathrm{MdhD}: 16 \mathrm{MdhF}: 26 \mathrm{Mdhl}-1 / \mathrm{Mdhl}-3$ was obtained from the open-pollinated population. This ratio was not significantly different from the expected ratio of 1:1:1:1 $\left(\mathrm{x}^{2}=3.94\right)$. The six seedlings in the $M d h A$ class probably were due to outcrossing with PI 113452 (MdhD) or PI $117679(M d h D)$, which overlapped in bloom slightly with PI 106062. Even though this population was not from a controlled cross, it further supports the hypothesis that the variation was due to polymorphism at a single locus.

Although segregation data indicated $\mathrm{MDH}$ variability is due to polymorphism at a single locus, banding patterns obtained were quite complex (Figs. 2 and 3). Observation of phenotypes obtained on HIS suggests how the various banding patterns may be produced. Previous investigators (Arulsekar et al., 1986b; Durham et al., 1987) have determined that MDH is a dimeric enzyme in peach and band 13 is the mitochondrial form of the enzyme. Due to cellular compartmentalization, mitochondrial $\mathrm{MDH}$ does not produce heterodimeric bands with other forms of MDH (Goodman et al., 1980a). Therefore, band 13 may be excluded from consideration when determining production of heterodimeric bands between nonmitochondrial MDHs.

Segregation ratios observed in this study support the hypothesis that MDH is controlled by two loci in peach, as previously proposed (Arulsekar et al., 1986a; Durham et al., 1987). The Mdh2 locus appears to be monomorphic and responsible for production of the mitochondrial band, while Mdhl is polymorphic and responsible for the variation observed in peach. From the $M d h A, M d h B$, and $M d h C$ phenotypes, it can be deduced that the alleles produce two proteins in the homozygous state that can interact to produce heterodimeric and homodimeric bands. In the $M d h A$ phenotype, bands 14 and 11 were probably homodimeric, whilq 12 was heterodimeric. Likewise, bands 6 and 10 were homodimeric and 9 was heterodimeric in the $M d h B$ phenotype. Since band 1 consistently stained more darkly than other bands, it possibly was produced by comigration of more than a single band. We propose that band 1 is actually produced by comigration of two monomeric bands and a heterodimeric band. The origin of band 7 is not known; how- ever, it does not seem to interact with other proteins to produce heterodimeric bands and was peculiar to the $M d h A, M d h C$, and $M d h F$ phenotypes. Band 7 did not appear to be present in any phenotype produced by the Mdhl-2 allele in the homozygous or heterozygous state. Band 8 in the $M d h D$ phenotype was a heterodimeric band produced between bands 11 and 6 , from the Mdhl-3 and $M d h l-2$ alleles, respectively. The heterodimeric band produced by interaction of the proteins responsible for bands 6 and 14 probably was obscured by comigration with bands 10 and 11. Likewise, the heterodimeric band produced by interaction of the proteins producing bands 10 and 11 is also obscured due to comigration. Band 10.5 on $\mathrm{MC}$ was probably a heterodimeric band produced by interaction of the proteins producing bands 14 and 6 . In the $M d h E$ phenotype, bands 2 and 3 are heterodimeric bands. Band 2 was produced by interaction of the proteins producing bands 1 and 6 , while band 3 was produced by the interaction of the proteins producing bands 1 and 10. In the $M d h F$ phenotype, bands 4 and 5 are heterodimeric bands produced by the interaction of the proteins producing bands 11 and 1 and 14 and 1 , respectively.

The $M d h l-3, M d h l-2$, and $M d h l-1$ alleles were present in the plant introductions at frequencies of $0.25,0.67$, and 0.08 , respectively. As observed in IDH, heterozygous genotypes were present at a much lower frequency than homozygous genotypes. The genotypes of each clone are given in Table 1. It is interesting that we found no report of $M d h l-3$ in North American cultivars and breeding programs, since it was the second most frequent allele in the plant introductions and the most frequent allele in clones originating directly from China. This may be due to the narrow germplasm base of the North American cultivars (Scorza et al., 1985), or perhaps to reduced viability of the genotype in certain genetic backgrounds under North American climatic conditions.

Shikimate dehydrogenase. Two SDH banding patterns were observed in the plant introductions (Fig. 4). All of the plant introductions displayed a single band, except for PI 117679, PI 113452, and PI 113650, which possessed a slower-migrating band in addition to the band present in the rest of the plant introductions. Faint bands were sometimes detected migrating ahead and behind the main region of activity, but they were not consistent enough to characterize. The single-banded phenotype was referred to as $S d h A$, and the double-banded phenotype as $S d h B$. The $R_{m}$ values of the two bands were 1.00 and 0.89 . 


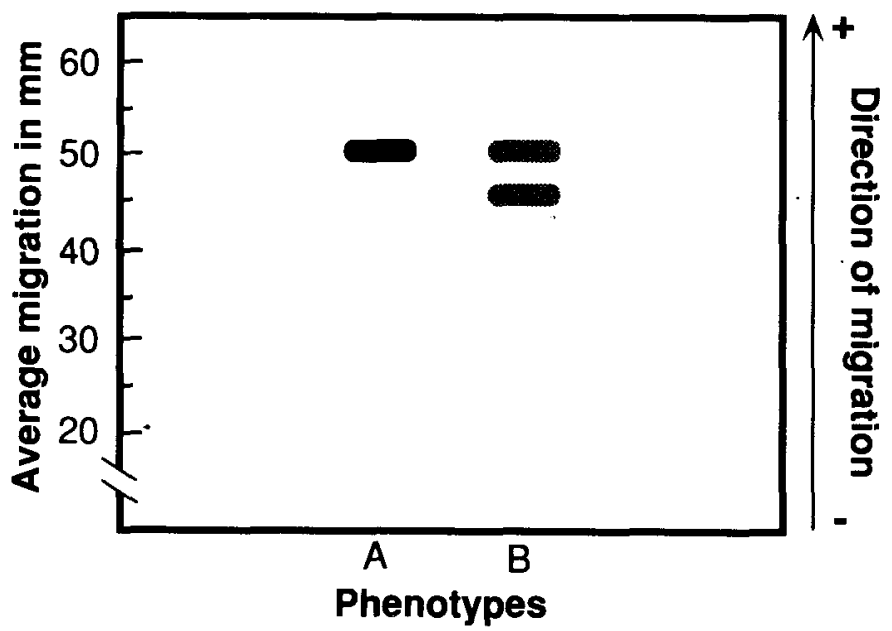

Fig.4. Diagram of $\operatorname{SdhA}(\mathrm{A}) \mathrm{a} \operatorname{SdhB}(\mathrm{B})$ shikimated dehydrogenase phenotypes observed in peach plant introductions.

Two crosses [PI $146137(\mathrm{SdhA}) \times$ PI $117679(\mathrm{SdhB})$ and PI $65974(\mathrm{Sdh} A) \times$ PI $117679(\mathrm{SdhB})]$ were made to determine inheritance of SDH, but fruit set on these crosses was poor. Although fewer seedlings were obtained in these crosses, the observed ratio of $23 \operatorname{Sdh} A: 21 \operatorname{SdhB}$ obtained in the cross of PI $146137 \times$ PI 117679 was close to a $1: 1$ ratio $\left(x^{2}=0.09\right.$ NS), indicating that SDH is monomeric and encoded by one locus. Allelic designations of $S d h l-2$ and $S d h l-3$ were given because a faster-migrating $S d h l$ allele is present in species closely related to peach and almond (Mowrey, unpublished data). The cross of PI $65974 \times$ PI 117679 gave a considerably different ratio of $21 \operatorname{Sdh} A: 7 \operatorname{Sdh} B\left(x^{2}=10.05 * *\right)$. The cause of this discrepancy is not known.

PI 117679, PI 113452, and PI 113650 were also heterozygous at both LAP loci and both PGD loci. PI 113650 was also heterozygous at, the Pgm2 and Aat2 loci. Peach is monomorphic at these loci, while almond possesses contrasting alleles (Arulsekar et al., 1986a; Chaparro et al., 1987; Hauagge et al., 1987). Comparison with almond clones of known genotype indicated PI 117679, PI 113452, and PI 113650 were heterozygous for almond alleles at Lapl, Lap2, Pgd1, and Pgd2. PI 113650 was also heterozygous for the slow Pgm2 and Aat2 alleles present in almond. These clones have phenotypes resembling peach $\times$ almond hybrids and are probably of interspecific origin. This relationship suggests that the $S d h 1-3$ allele is of almond origin.

The probable hybrid origin of PI 117679 and PI 113452 might be responsible for the poor fruit set obtained when these clones were used as pollen parents. This origin may also be the reason for the skewing toward the $S d h 1-2 / S d h 1-2$ genotype observed in the cross of PI $65974 \times$ PI 117679. Backcrossing interspecific hybrids of Lycopersiccm sometimes results in anomalous segregation ratios at isozyme loci (Vallejos and Tanksley, 1983). This phenomenon was also observed in segregation ratios of both PGD loci in the cross PI $146137 \times$ PI 117679 . PGD is inherited in a Mendelian manner in $\mathrm{F}_{\mathrm{I}}$ peach $\mathrm{x}$ almond hybrids (Chaparro et al., 1987), but ratios of 30 Pgdl-2/Pgdl-2:17 (Pgd1-1/Pgd1-2 $\left(x^{2}=4.28^{*}\right)$ and 14 Pgd2-1/Pgd2-2: 33 Pgd2$1 / P g d 2-1 \quad\left(x^{2}=6.58^{*}\right)$ were observed at the PGD loci. In each of these cases, the peach genotype was the most common in the seedling population. Accidental self-pollination does not appear to be the cause of this phenomenon, because the Mdhl segre- gation ratio in cross PI $65974 \times$ PI 117679 was as expected, and PI 146137 is male-sterile.

The cross PI $146137 \times$ PI 117679 was examined for possible linkages, because the pollen parent was heterozygous at six loci and the female parent was homozygous at these loci. Pgdl, $P g d 2$, and $M d h 1$ could not be included in the test due to abnormal segregation ratios. The Lapl and Lap2 loci appear to be linked, (5 Lap1-1/Lap1-I Lap2-2/Lap2-3: 16 Lap1-1/Lap1-1 Lap2-3/Lap2-3: 17 Lap1-1/Lap1-2 Lap2-21Lap2-3: 3 Lap1-1/ Lapl-2 Lap2-3/Lap2-3, with $x^{2}=14.33^{* *}$ ) as reported by Hauagge et al (1987). No other linkages were detected.

This study identified new genetic markers at two loci (IdhI and Mdh1) in peach. The Mdhl-3 allele will not be as useful for linkage studies as the IdhI alleles, since it is allelic to previously reported $\mathrm{MDH}$ variants. Previous workers have suggested lack.of isozyme variability in peach is due to the narrow genetic base of North American cultivars and breeding programs. Findings of this study indicate little isozyme variation is present in the species as a whole, since clones originating in 16 countries, including 12 clones from the center of diversity of peach, were examined.

Considerable isozyme polymorphism is present in almond (Arulsekar et al., 1986a; Chaparro et al., 1987; Hauagge et al., 1987), P. davidiana, P. kansuensis, and P. mira (B. D. M., unpublished data) that could be used, through interspecific hybridization, for genetic mapping in peach. Skewed segregation ratios observed when peach $\times$ almond hybrids were backcrossed to peach indicate care must be taken when using this approach to avoid biased results. One possible way to avoid skewing of segregation ratios would be to use as many peach clones and interspecific hybrids as feasible, because skewing may be more pronounced in certain genetic backgrounds. Male-sterile parents should also be used when possible, to avoid accidental selfpollination.

\section{Literature Cited}

Ackerman, W.L. 1957. Series I. Evaluation of foreign fruit and nuts. No. 8. Late blossoming peach and nectarine varieties tested at Chico, California. U.S. Plant Intro. Garden, Chico, Calif. Crops Res. Div. ARS/USDA.

Ackerman, W. L., L.D. Joley, and D. Halsey. 1955. Series 1. Evaluation of foreign fruit and nuts. No. 2. Peaches and nectarines. Blossoming and leafing responses of foreign and domestic peaches and nectarines to temperature. U.S. Plant Intro. Garden, Chico, Calif. Crops Res. Div. ARS/USDA.

Arulsekar, S. and D.E. Parfitt. 1986. Isozyme analysis procedures for stone fruits, almond, grape, walnut, pistachio, and fig. HortScience 21:928-933.

Arulsekar, S., D.E. Parfitt, and D.E. Kester. 1986a. Comparison of isozyrne variability in peach and almond cultivars. J. Hered. 77:272274.

Arulsekar, S., D.E. Parfitt, W. Beres, and P.E. Hansche. 1986b. Genetics of malate dehydrogenase isozymes in peach. J. Hered. 77:4951.

Bosch, A., C. Vega, and C. Benito. 1987. The peroxidase isozymes of the wheat kernel: Tissue and substrate specificity and their chromosomal locations. Theor. Applied Genet. 73:701-706.

Chaparro, J. X., R.E. Durham, G.A. Moore, and W.B. Sherman. 1987. Use of isozyme techniques to identify peach $\times$ 'Nonpareil' almond hybrids. HortScience 22:300-302.

Conkle, M.T., P.D, Hodgskiss, L.B. Nunnally, and S.C. Hunter. 1982. Starch gel electrophoresis of conifer seeds: A laboratory manual. USDA For. Serv. Gen. Tech. Rpt. PSW-64.

Durham, R. E., G.A. Moore, and W.B. Sherman. 1987. Isozyme band- 
ing patterns and their usefulness as genetic markers in peach. J. Amer. Soc. Hort. Sci. 112:1013-1018.

Goodman, M. M., C.W. Stuber, C.N. Lee, and F.M. Johnson. 1980a. Genetic control of malate dehydrogenase isozymes in maize. Genetics 94:153-168.

Goodman, M. M., C.W. Stuber, K. Newton, and H.H. Weissinger. 1980b. Linkage relationships of 19 enzyme loci in maize. Genetics 96:697-710.

Hauagge, R., D.E. Kester, and R.A. Asay. 1987. Isozyme variation among California almond cultivars: I. Inheritance. J. Amer. Sot. Hort. Sci. 112:687-693.

Hesse, C.O. 1975. Peach, p. 285-335. In: J. Janick and J. Moore (eds.)." Advances in fruit breeding. Purdue Univ. Press, West Lafayette, Ind.

Messeguer, R., P. Arus, and M. Carrera. 1987. Identification of peach cultivars with pollen isozymes. Scientia Hort. 31:107-117.

Monet, R., Y. Bastard, and B. Gibault. 1985. Etude genetique et amelioration des pechs plates. Agronomic 5:727-731.

Scorza, R., S.A. Mehlenbacher, and G. W. Lightner. 1985. Inbreeding and coancestry of freestone peach cultivars of the eastern United States and implications for peach germplasm improvement. J. Amer. Soc. Hort. Sci. 110:547-552.

Stuber, C. W., J.F. Wendel, M.M. Goodman, and J.S.C. Smith. 1988. Techniques and scoring procedures for starch gel electrophoresis of enzymes from maize (Zea mays L.). N.C. Agr. Res. Serv. Tech. Btd. 286.

Tanksley, S.D. and C.M. Rick. 1980. Isozymic linkage map of the tomato: Applications in genetics and breeding. Theor. Applied Genet. 57:161-170.

Tanksley, S. D., D. Zamir, and R.C. Rick. 1981. Evidence for extensive overlap of sporophytic and gametophytic gene expression in Lycopersicon esculentum. Science 213:453455.

Vallejos, C.E. and S.D. Tanksley. 1983. Segregation of isozyme markers and cold tolerance in an interspecific backcross of tomato. Theor. Applied Genet. 66:241-247.

Zeven, A.C. and P.M. Zhukovsky. 1975. Dictionary of cultivated plants and their centres of diversity. Centre for Agricultural Publishing and Documentation, Wageningen, Netherlands. 